\title{
Emerging impact of the long noncoding RNA MIR22HG on proliferation and apoptosis in multiple human cancers
}

\author{
Le Zhang ${ }^{\dagger}$, Cuixia $\mathrm{Li}^{\dagger}$ and Xiulan Su${ }^{*}$
}

\begin{abstract}
An increasing number of studies have shown that long noncoding RNAs (IncRNAs) play important roles in diverse cellular processes, including proliferation, apoptosis, migration, invasion, chromatin remodeling, metabolism and immune escape. Clinically, the expression of MIR22HG is increased in many human tumors (colorectal cancer, gastric cancer, hepatocellular carcinoma, lung cancer, and thyroid carcinoma), while in others (esophageal adenocarcinoma and glioblastoma), it is significantly decreased. Moreover, MIR22HG has been reported to function as a competitive endogenous RNA (ceRNA), be involved in signaling pathways, interact with proteins and interplay with miRNAs as a host gene to participate in tumorigenesis and tumor progression. In this review, we describe the biological functions of MIR22HG, reveal its underlying mechanisms for cancer regulation, and highlight the potential role of MIR22HG as a novel cancer prognostic biomarker and therapeutic target that can increase the efficacy of immunotherapy and targeted therapy for cancer treatment.
\end{abstract}

Keywords: Long noncoding RNAs, MIR22HG, Tumorigenesis, Therapeutic target

\section{Background}

With the development of genome-wide sequencing technology, there is a deeper understanding of the transcriptomes of organisms. It is currently believed that $>90 \%$ of noncoding RNAs (ncRNAs) in the human genome play important biological roles, whereas they were previously considered "transcriptional noise" or "transcriptional waste" [1,2]. Depending on their length, ncRNAs can be divided into two classes, small noncoding RNAs (ncRNA $<200 \mathrm{nt}$ ), including miRNAs, siRNAs, and piRNAs, and long noncoding RNAs (lncRNAs $>200 \mathrm{nt}$ ), both of which lack the ability to encode proteins [3]. An increasing number of studies have shown that lncRNAs play important roles in regulating important cell biological functions, such as cell proliferation, apoptosis,

\footnotetext{
* Correspondence: xlsu@hotmail.com

'Le Zhang and Cuixia Li contributed equally to the manuscript.

Clinical Medical Research Center of the Affiliated Hospital, Inner Mongolia Medical University, 1 Tong Dao Street, Huimin District, Inner Mongolia 010050 Hohhot, China
}

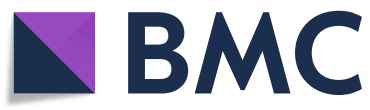

( The Author(s). 2020 Open Access This article is licensed under a Creative Commons Attribution 4.0 International License, which permits use, sharing, adaptation, distribution and reproduction in any medium or format, as long as you give appropriate credit to the original author(s) and the source, provide a link to the Creative Commons licence, and indicate if changes were made. The images or other third party material in this article are included in the article's Creative Commons licence, unless indicated otherwise in a credit line to the material. If material is not included in the article's Creative Commons licence and your intended use is not permitted by statutory regulation or exceeds the permitted use, you will need to obtain permission directly from the copyright holder. To view a copy of this licence, visit http://creativecommons.org/licenses/by/4.0/. The Creative Commons Public Domain Dedication waiver (http://creativecommons.org/publicdomain/zero/1.0/) applies to the data made available in this article, unless otherwise stated in a credit line to the data. sponse $[4,5]$. In addition, the abnormal expression of IncRNAs, such as MALAT1, HOTAIR, H19 and TUG1, is closely related to the occurrence and development of various malignant tumors $[6,7]$. This article summarizes the related research reports on MIR22HG in common tumors, summarizes its biological functions and potential mechanisms in tumors, and provides clues for its application in diagnosis, efficacy and prognosis.

LncRNAs are regulatory RNAs with a length greater than $200 \mathrm{nt}$ and lack protein-coding potential. Increasing evidence has shown that IncRNAs regulate the molecular processes of tumors at the transcriptional, translational, and epigenetic levels. If located in the cytoplasm, lncRNAs may play a regulatory role in "stabilizing RNAs", "regulating mRNA translation", acting as "ceRNAs", "acting as miRNA precursors" or "mediating protein modifications" [8]; if located in the nucleus, lncRNAs play a regulatory role in two ways: "cis-acting" or "trans-acting" $[9,10]$. 
Furthermore, certain lncRNAs show cell- and tissuespecific expression patterns that are critical for their functional analysis and exploration of the potential of lncRNAs as diagnostic, prognostic, and therapeutic targets in cancer [11-18]. Many lncRNAs and their functions or mechanisms need to be further studied, some of which have currently highly attracted the attention of researchers.

In this review, we note that IncRNA NR 028502.1 is located in $17 \mathrm{p} 13.3$, a chromosomal region that is frequently deleted or hypermethylated or shows loss of heterozygosity $[19,20]$. NR 028502.1 was identified as a lncRNA in the Encyclopedia of DNA Elements (ENCODE) project and is currently annotated as being discovered. It has four different transcripts: MIR22HG-1 (2659 bp, transcript variant 1), MIR22HG-2 (1852 bp, transcript variant 2), MIR22HG-3 (1439 bp, transcript variant 3), and MIR22HG-4 (1356 bp, transcript variant 4). Existing studies have shown that MIR22HG functions as a tumor suppressor in many cancers, such as gastric cancer, colorectal cancer, esophageal cancer, lung cancer and hepatocellular carcinoma. However, in esophageal adenocarcinoma and glioblastoma, MIR22HG acts as a tumor promoter to facilitate tumor progression. Considering the differential expression and significant biological function of MIR22HG, it may have great value for diagnostic, prognostic, and therapeutic cancer research. Therefore, in-depth research on the roles of MIR22HG in different tumors and its possible mechanisms of action will provide new insight into clinical cancer treatment. This article provides an overview of existing research on MIR22HG and highlights its promising clinical application as a potential biomarker for the prevention, diagnosis and treatment of cancer.

\section{Regulatory mechanisms of MIR22HG in cancer}

Studies so far suggest that lncRNAs play critical roles in both normal cellular functions and diseases, including cancer. MIR22HG, a well-studied lncRNA, has been shown to function as a master regulator in diverse malignancies and thus can play a critical role in various aspects of carcinogenesis, including proliferation, apoptosis, invasion, and metastasis (Table 1). Importantly, the aberrant expression of MIR22HG is significantly associated with important clinical characteristics, such as advanced tumor size, stage, TNM stage and overall survival in various kinds of human cancer (Table 2). Various mechanisms have been implicated in the MIR22HG-mediated regulation of cancer progression; for example, MIR22HG has been reported to function as a competitive endogenous RNA (ceRNA) (Fig. 1a), be involved in signaling pathways (Fig. 1b), interact with proteins (Fig. 1c) and interplay with miRNAs as a host gene (Fig. 1d).

\section{Function as a ceRNA}

One of the most well-characterized mechanisms of IncRNAs is functioning as a ceRNA or "sponge" for miRNAs. ceRNAs are involved in posttranscriptional regulation, as they compete with miRNAs through the same miRNA sequence during RNA transcription to regulate the expression of downstream target genes [32-

Table 1 Functional characterization of MIR22HG in various tumors

\begin{tabular}{|c|c|c|c|c|c|}
\hline Tumor type & Expression & Role & Functional role & Related genes and pathways & References \\
\hline thyroid carcinoma & $\begin{array}{l}\text { down } \\
\text { regulated }\end{array}$ & $\begin{array}{l}\text { tumor } \\
\text { suppressor }\end{array}$ & $\begin{array}{l}\text { cell proliferation, migration, invasion } \\
\text { and apoptosis }\end{array}$ & $\begin{array}{l}\text { Hippo signaling pathway, } \\
\text { miR-24-3p and } \\
\text { p27kip1 }\end{array}$ & {$[21,22]$} \\
\hline $\begin{array}{l}\text { hepatocellular } \\
\text { carcinoma }\end{array}$ & $\begin{array}{l}\text { down } \\
\text { regulated }\end{array}$ & $\begin{array}{l}\text { tumor } \\
\text { suppressor }\end{array}$ & $\begin{array}{l}\text { cell proliferation, migration, and } \\
\text { invasion }\end{array}$ & $\begin{array}{l}\text { miR-22-3p, HMGB1, HuR, } \\
\text { miR-10a-5p, NCOR2, } \beta \text {-catenin and EMT }\end{array}$ & {$[23,24]$} \\
\hline $\begin{array}{l}\text { endometrial } \\
\text { carcinoma }\end{array}$ & $\begin{array}{l}\text { down } \\
\text { regulated }\end{array}$ & $\begin{array}{l}\text { tumor } \\
\text { suppressor }\end{array}$ & $\begin{array}{l}\text { cell proliferation, apoptosis and the } \\
\text { cell cycle }\end{array}$ & miR-141-3p and DAPK1 & {$[25]$} \\
\hline cholangiocarcinoma & $\begin{array}{l}\text { down } \\
\text { regulated }\end{array}$ & $\begin{array}{l}\text { tumor } \\
\text { suppressor }\end{array}$ & $\begin{array}{l}\text { cell proliferation, migration, and } \\
\text { invasion }\end{array}$ & $\begin{array}{l}\text { Wnt/ } \beta \text {-catenin signaling pathway, } \beta \text {-catenin, } \\
\text { cyclin D1 and c-myc }\end{array}$ & {$[26]$} \\
\hline $\begin{array}{l}\text { colorectal } \\
\text { cancer }\end{array}$ & $\begin{array}{l}\text { down } \\
\text { regulated }\end{array}$ & $\begin{array}{l}\text { tumor } \\
\text { suppressor }\end{array}$ & $\begin{array}{l}\text { cell proliferation } \\
\text { and migration }\end{array}$ & $\begin{array}{l}\text { SMAD2, SMAD4, TGF } \beta \text { signaling pathway, } \\
\text { EMT, and CD8A }\end{array}$ & {$[27]$} \\
\hline gastric cancer & $\begin{array}{l}\text { down } \\
\text { regulated }\end{array}$ & $\begin{array}{l}\text { tumor } \\
\text { suppressor }\end{array}$ & $\begin{array}{l}\text { cell proliferation, migration, and } \\
\text { invasion }\end{array}$ & Notch2 signaling pathway and HEY1 & {$[28]$} \\
\hline $\begin{array}{l}\text { esophageal } \\
\text { adenocarcinoma }\end{array}$ & $\begin{array}{l}\text { up } \\
\text { regulated }\end{array}$ & $\begin{array}{l}\text { tumor } \\
\text { promoter }\end{array}$ & $\begin{array}{l}\text { cell } \\
\text { proliferation, migration, invasion and } \\
\text { apoptosis }\end{array}$ & STAT3, c-Myc and p-FAK & {$[29]$} \\
\hline $\begin{array}{l}\text { non-small cell lung } \\
\text { cancer }\end{array}$ & $\begin{array}{l}\text { down } \\
\text { regulated }\end{array}$ & $\begin{array}{l}\text { tumor } \\
\text { suppressor }\end{array}$ & $\begin{array}{l}\text { cell proliferation, migration, and } \\
\text { invasion }\end{array}$ & Ybx1, MET, and p21 & {$[30]$} \\
\hline glioblastoma & $\begin{array}{l}\text { up } \\
\text { regulated }\end{array}$ & $\begin{array}{l}\text { tumor } \\
\text { promoter }\end{array}$ & $\begin{array}{l}\text { cell proliferation and } \\
\text { invasion }\end{array}$ & $\begin{array}{l}\text { MiR-22-3p/miR-22-5p, } \\
\text { SFRP2/PCDH15, } \\
\text { ACIL6JTK and } \\
\text { Wnt/ß-catenin signaling pathway }\end{array}$ & {$[31]$} \\
\hline
\end{tabular}


Table 2 Clinical significance of MIR22HG in various human tumors

\begin{tabular}{|c|c|c|}
\hline Cancer type & Clinicopathological features & References \\
\hline \multirow[t]{2}{*}{ thyroid carcinoma } & $\begin{array}{l}\text { Low MIR22HG expression was related to tumor size }(P=0.015) \text {, TNM stage }(P=0.022) \text { and poor overall survival } \\
(P=0.030) \text {. }\end{array}$ & [21] \\
\hline & $\begin{array}{l}\text { Low MIR22HG expression was significantly related to the lymph node metastasis status }(P<0.01) \text {, the residual } \\
\text { tumor status }(P<0.05) \text {, N stage }(P<0.05) \text {, tumor grade }(P<0.001) \text { and T stage }(P<0.001) \text { while high MIR22HG } \\
\text { expression was significantly correlated with the disease recurrence rate }(P<0.01) \text {, overall survival time }(P=0.0665) \\
\text { and disease-free survival time }(P<0.05) \text { in TC by analyzing TCGA, the GSE29265, GSE33630, and GSE55091 public } \\
\text { datasets. }\end{array}$ & [22] \\
\hline \multirow[t]{2}{*}{$\begin{array}{l}\text { hepatocellular } \\
\text { carcinoma }\end{array}$} & $\begin{array}{l}\text { Low MIR22HG expression was associated with short overall survival }(P=0.045) \text { and poor disease-free survival }(P= \\
0.036) \text {. }\end{array}$ & [23] \\
\hline & $\begin{array}{l}\text { Patients with high MIR22HG expression exhibited better overall survival }(145 \text {-patient cohort: } P=0.001 \text {; TCGA } \\
\text { cohort: } P=0.015 \text { ) and disease-free survival (145-patient cohort: } P=0.042 \text {; TCGA cohort: } P=0.003 \text { ) than those with } \\
\text { low MIR22HG expression. }\end{array}$ & [24] \\
\hline cholangiocarcinoma & $\begin{array}{l}\text { Low MIR22HG expression was positively correlated with advanced clinical stage (TNM) }(P=0.039) \text {, large tumor size } \\
(P=0.002) \text {, lymph node metastasis }(P=0.0001) \text {, and poor overall survival }(P=0.020) \text {. }\end{array}$ & [26] \\
\hline $\begin{array}{l}\text { colorectal } \\
\text { cancer }\end{array}$ & $\begin{array}{l}\text { Low MIR22HG expression was significantly associated } \\
\text { with poor overall survival }(P=0.0008) \text { and disease-free survival }(P=0.0009) \text {. }\end{array}$ & [27] \\
\hline gastric cancer & Low MIR22HG expression indicated a low 5 -year overall survival rate $(P<0.05)$. & [28] \\
\hline $\begin{array}{l}\text { non-small cell lung } \\
\text { cancer }\end{array}$ & $\begin{array}{l}\text { Low MIR22HG expression was correlated with poor patient survival }(P=0.003) \text { in an independent UM cohort } \\
\text { including } 101 \text { LUAD tissues and } 27 \text { normal lung tissues. }\end{array}$ & [30] \\
\hline glioblastoma & $\begin{array}{l}\text { High MIR22HG expression was associated with patient age }(P<0.001) \text {, Karnofsky Performance Status score }(P< \\
0.001) \text {, advanced tumor grade and poor overall survival }(P<0.05) \text {. }\end{array}$ & [31] \\
\hline
\end{tabular}

34]. Mounting evidence has demonstrated that ceRNAs play a vital role in cancer progression [35-37].

More recently, MIR22HG has also emerged as exhibiting ceRNA functions in many cancer types, such as thyroid carcinoma (TC), endometrial carcinoma (EC) and hepatocellular carcinoma (HCC) (Fig. 2). Chen et al. revealed that MIR22HG was downregulated in TC tumor tissues compared with nontumor tissues using 40 pairs of papillary thyroid carcinoma tissues through qRT-PCR detection. Further biological function studies have demonstrated that MIR22HG suppresses the growth, migration and invasion of TC cells. Systematically, MIR22HG acts as a ceRNA to upregulate p27kip1 by directly binding with miR-24-3p, which inhibits the malignant phenotype of TC cells [21] (Fig. 2a). Moreover, the authors reported that low MIR22HG expression was related to tumor size $(P=0.015)$, TNM stage $(P=0.022)$ and poor overall survival $(P=0.030)$ by qRT-PCR detection. Another study by $Q$ in et al. verified these findings. They reported that the downregulation of MIR22HG was significantly related to the lymph node metastasis status $(P<0.01)$, the residual tumor status $(P<0.05), \mathrm{N}$ stage $(P<0.05)$, tumor grade $(P<0.001)$ and $\mathrm{T}$ stage $(P<0.001)$ while high MIR22HG expression was significantly correlated with the disease recurrence rate $(P<$ $0.01)$, overall survival time $(P=0.0665)$ and disease-free survival time $(P<0.05)$ in TC by analyzing TCGA, GSE29265, GSE33630, and GSE55091 public database. Coexpression, Gene Ontology (GO) and Kyoto Encyclopedia of Genes and Genomes (KEGG) pathway analyses revealed that MIR22HG was involved in regulating apoptosis, transcription, the cell cycle, and Hippo signaling [22].

Wu et al. found that MIR22HG was significantly decreased in $120 \mathrm{HCC}$ tissues compared with adjacent nontumor liver tissues by employing qRT-PCR. Furthermore, low MIR22HG expression was associated with short overall survival $(P=0.045)$ and poor disease-free survival $(P=0.036)$. These results implicated the potential role of MIR22HG as a diagnostic and prognostic biomarker to improve HCC patient outcomes. Functional experiments demonstrated that the knockdown of MIR22HG promoted the growth, migration and invasion of HCC cells. It has also been reported that miR-10a functions as an oncogene or tumor suppressor depending on the context [38-41]. Mechanistically, miR-10a-5p can be a downstream target of MIR22HG. By acting in this manner as a ceRNA, MIR22HG directly binds to miR-10a-5p and increases NCOR2 expression to inhibit the proliferation, migration and invasion of HCC cells [23] (Fig. 2b).

Not coincidentally, Cui's team confirmed the critical role by which MIR22HG acts as a ceRNA to modulate the proliferation, apoptosis and cell cycle of EC cells [25] (Fig. 2c). MIR22HG overexpression significantly reduced miR-141-3p expression in EC cells. Subsequently, MIR22HG increased DAPK1 expression by targeting miR-141-3p, thus inhibiting cell proliferation via G1 arrest of the cell cycle and promoting the apoptosis of EC cells. In summary, the MIR22HG-regulated miR-141-3p/ DAPK1 axis may be a new therapeutic target for the treatment and prevention of EC. 


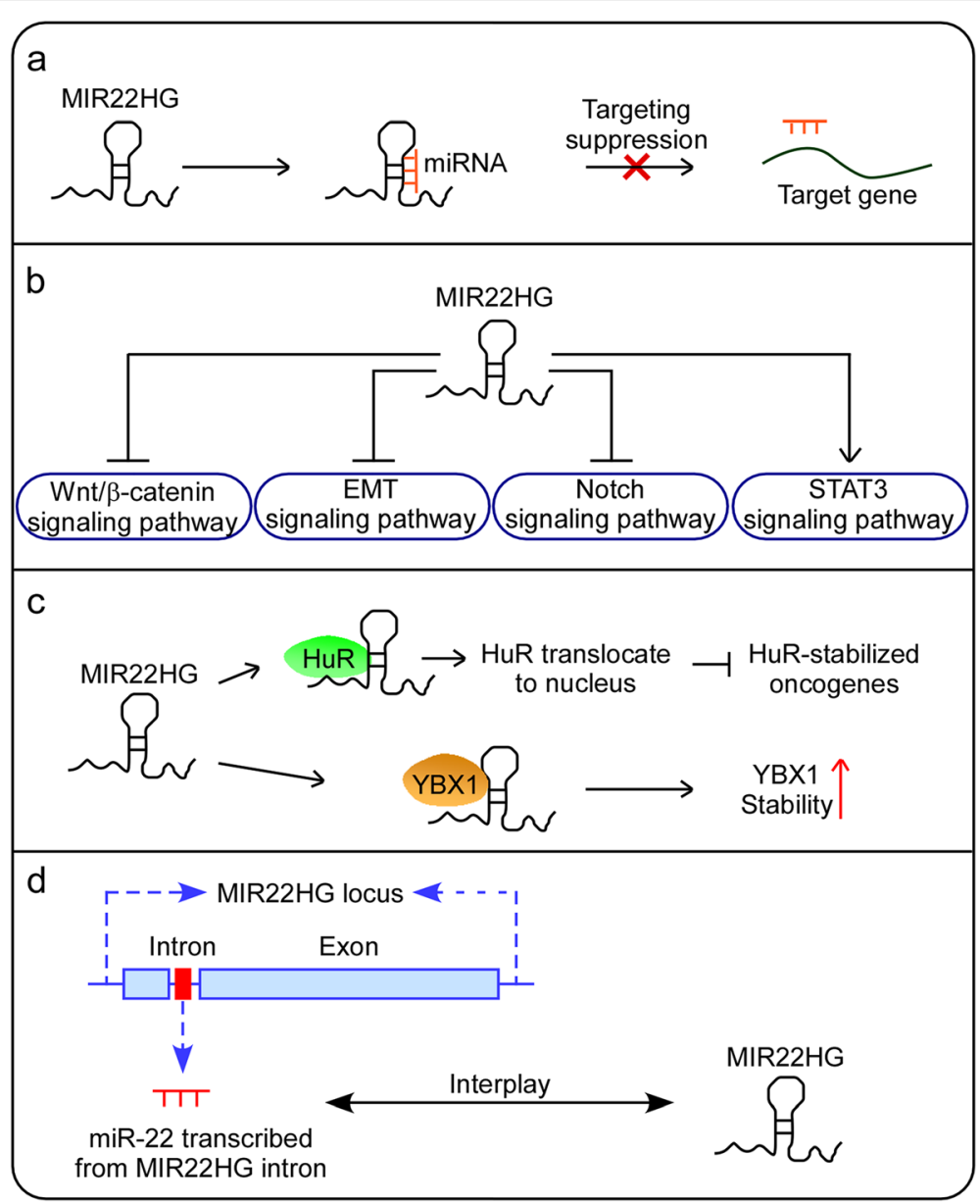

Fig. 1 Working mechanisms implicated in the MIR22HG-mediated regulation of cancer progression. a MIR22HG acts as a ceRNA. b MIR22HG is involved in signaling pathways. c MIR22HG interacts with proteins. d MIR22HG interplays with miRNAs as a host gene

\section{Involvement in signaling pathways}

Signaling pathways coordinate communication to enable cells to respond to intracellular or extracellular stimuli. There are many different signaling pathways that contribute to development and cellular homeostasis [4244]. In diseases, especially cancer, aberrant signaling has been identified as a key mechanism of cancer progression and metastasis [45]. Growing evidence suggests that the MIR22HG-mediated dysregulation of signaling pathways is central to many different types of cancer (Fig. 3).

\section{Wnt/ß-catenin signaling pathway}

$\mathrm{Wnt} / \beta$-catenin signaling is an evolutionarily conserved regulatory pathway that has diverse roles in governing cell fate, proliferation, migration, polarity, and death [46, 47]. Accumulating evidence has shown that inappropriate activation of the $\mathrm{Wnt} / \beta$-catenin pathway is an important mechanism for cancer progression [48-51], and therapeutics targeting $\mathrm{Wnt} / \beta$-catenin signaling have shown promising clinical applications [52-54].
A report by Hu et al. showed that MIR22HG was downregulated in cholangiocarcinoma (CCA) issues and cell lines by RT-qPCR. The low expression of MIR22HG in CCA tissues was positively correlated with an advanced clinical stage (TNM) $(P=0.039)$, large tumor size $(P=$ $0.002)$, lymph node metastasis $(P=0.0001)$, and poor overall survival $(P=0.020)$ [26]. The $\mathrm{Wnt} / \mathrm{\beta}$-catenin signaling pathway is involved in the regulation of downstream cmyc, cyclin D1 and other oncogenes that play an important role in tumor cell proliferation and apoptosis $[55,56]$. Importantly, the proto-oncogene c-myc is a vital cell cycle regulator in DNA synthesis and cell cycle progression [57, 58]. Hu et al. reported that MIR22HG negatively regulated the $\mathrm{Wnt} / \beta$-catenin signaling pathway by downregulating the expression of $\beta$-catenin, cyclin D1 and c-myc, leading to the inhibition of cell proliferation, migration and invasion in CCA cells. Further in vivo studies in which mouse subcutaneous xenografts were used confirmed that MIR22HG suppresses CCA tumorigenesis (Fig. 3a). In conclusion, MIR22HG may be a novel target for diagnosis and therapy in CCA [26]. 


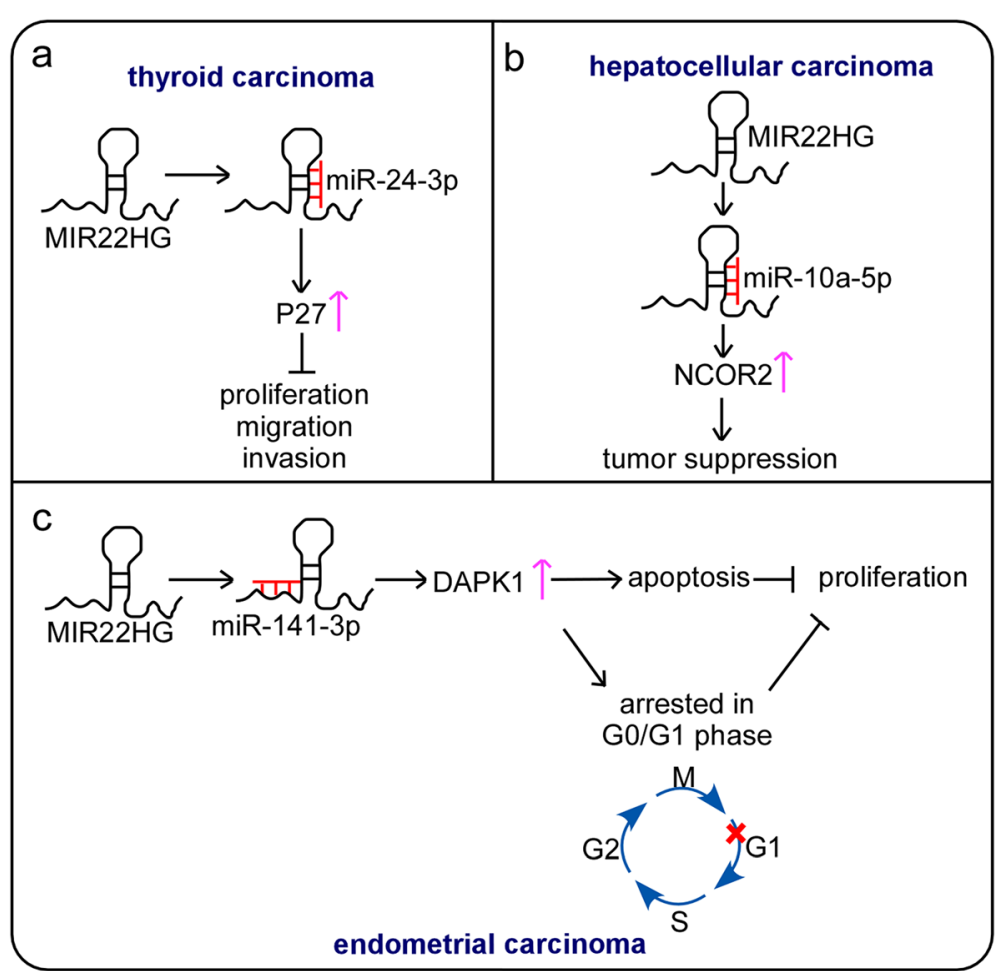

Fig. 2 MIR22HG functions as a ceRNA in human cancers. a MIR22HG functions as an endogenous sponge of miR-24-3p to increase the expression of p27, suppressing the proliferation, migration and invasion of TC. $\mathbf{b}$ MIR22HG acts as a ceRNA to bind with miR-10a-5p to increase the expression of NCOR2 and inhibit HCC progression. c MIR22HG functions as a ceRNA to bind with miR-141-3p to upregulate DAPK1 expression levels, resulting in EC cell proliferation inhibition

Epithelial-mesenchymal transition (EMT) signaling pathway EMT is a biological process in which epithelial cells lose their characteristic apical-basal polarity and markers while acquiring the characteristics of mesenchymal cells, with high migration and invasion abilities [59]. In recent years, EMT has become a hot spot of cancer research because of its roles in the initial process of tissue carcinogenesis. EMT markers are closely associated with the EMT process and EMT-related migration, invasion, proliferation, antiapoptosis, stemness, and tumor radio/ chemosensitivity of cancer cells $[60,61]$.

$\mathrm{Xu}$ et al. reported that MIR22HG was downregulated in colorectal cancer (CRC) tissues and cells compared with normal tissues and cells, as determined by qRTPCR [27]. Functional analyses revealed that MIR22HG inhibits CRC cell proliferation, migration and invasion in vitro. Then, the authors employed mouse subcutaneous xenograft models and three metastasis models, namely, an intestine metastasis mouse model, a lung metastasis mouse model and an orthotopic hepatic metastasis mouse model, to examine the effect of MIR22HG on tumor growth and metastasis in vivo. The results indicated that tumors formed by MIR22HG-overexpressing cells were smaller and weighed less than tumors formed by control cells and exhibited fewer metastatic nodules and sparse and small metastatic foci. Moreover, they discovered that MIR22HG overexpression inhibited the EMT process, and MIR22HG silencing produced the opposite effect. Silencing MIR22HG decreased the expression of epithelial markers (E-cadherin, ZO-1 and Occludin) and increased the expression of mesenchymal markers (N-cadherin, vimentin and fibronectin). Systematically, MIR22HG inhibits the interaction between SMAD2 and SMAD4 of the TGF $\beta$ pathway. Blocking the formation of the SMAD complex also prevents its binding to the promoter of SNAI1 and further suppresses the EMT process (Fig. 3b). These results imply that the MIR22HG-mediated SMAD2/4-SNAI1 axis plays a critical role in CRC progression by regulating EMT signaling pathways. Importantly, an increasing body of evidence has shown that the TGF $\beta$ pathway can reshape the immune environment of tumors $[62,63]$. The authors further investigated the function of MIR22HG in immune using syngeneic immunocompetent mouse model C57BL/6 [27]. The combination of MIR22HG and aPD-L1 enhanced sensitivity to immunotherapy, suppressed tumor growth, and prolonged the overall survival of mice by promoting CD8 $\mathrm{T}$ cell infiltration and facilitating immunotherapy in CRC. These observations indicate the potential application of 


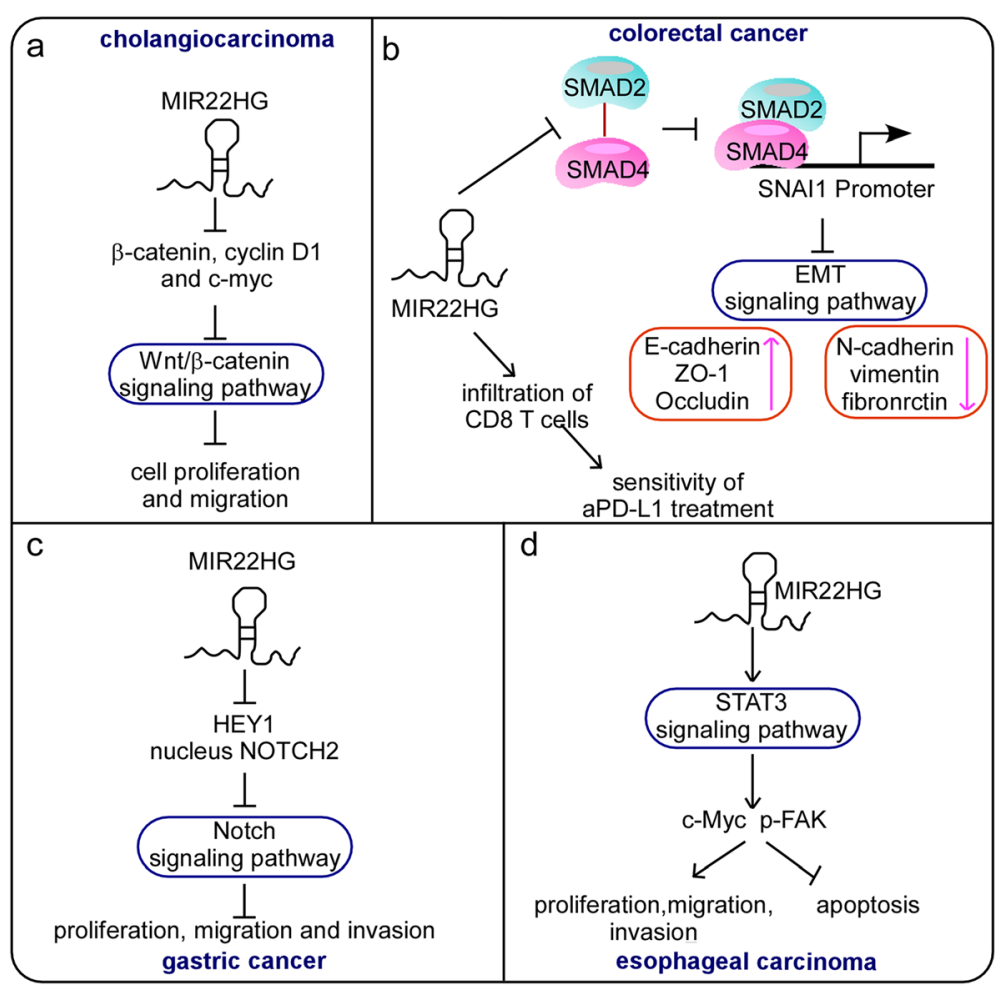

Fig. 3 MIR22HG is involved in signaling pathways that affect cancer progression. a MIR22HG negatively regulates the Wnt/ $\beta$-catenin signaling pathway by downregulating the expression of $\beta$-catenin, cyclin D1 and c-myc to inhibit cell proliferation and migration in CCA. b MIR22HG blocks the SMAD complex, preventing its binding to the promoter of SNAl1 and further suppressing the EMT signaling pathway. c MIR22HG inhibits the Notch signaling pathway by downregulating nuclear Notch2 and HEY1 expression in GC. d MIR22HG activates the STAT3 signaling pathway to promote the proliferation, migration and invasion of ESCA

MIR22HG in CRC immunotherapy by acting as a tumor suppressor.

\section{Notch signaling pathway}

The Notch family is a highly conserved and important transmembrane signaling protein family involved in cell development, differentiation, proliferation and apoptosis [64]. The role of Notch signaling in cancer is highly context-dependent [65]. It can act as an oncogene in $\mathrm{T}$ cell acute lymphoblastic leukemia (T-ALL), breast cancer, and ovarian cancer, while it can also exerts an important tumour-suppressor function in other cancers, such as HCC, forebrain glioma, and head and neck squamous cell carcinoma (HNSCC) [66, 67]. Given its complicated role in tumorigenesis, the Notch signaling pathway will need to be explored in more detail.

$\mathrm{Li}$ et al. reported that MIR22HG was downregulated in 43 pairs of human gastric cancer (GC) tissues compared to 21 pairs of matched normal tissues by RT-qPCR [28]. Clinicopathological analysis showed that low MIR22HG expression correlated with poor 5-year overall survival $(\mathrm{P}<0.05)$ in GC patients. The authors found that upregulated MIR22HG may suppress GC cell proliferation, invasion and migration in vitro. In addition, a mechanistic investigation revealed that MIR22HG negatively regulates $\mathrm{NOTCH} 2$ signaling by downregulating the expression of HEY1 and nuclear NOTCH2 [28]. MIR22HG knockdown did not influence the expression of $\mathrm{NOTCH} 2$ but markedly enhanced that of nuclear $\mathrm{NOTCH}$. These data suggest that MIR22HG inhibits GC progression by attenuating $\mathrm{NOTCH} 2$ signaling (Fig. 3c).

\section{STAT3 signaling pathway}

The STAT3 signaling pathway has been demonstrated to be important for cancer progression. First, it transduces signals from numerous receptor and nonreceptor tyrosine kinases that are frequently activated in cancer cells [68]. Second, as a transcription factor, STAT3 regulates the expression of many oncogenes, such as c cyclin B1, CDC2, p53, MCL-1, survivin, VEGF, BCL2 and BAX [69]. Third, growing evidence suggests that STAT3 signaling plays a crucial role in the suppression of tumor immune surveillance and may be a candidate therapeutic target for multiple antitumor immune responses [70]. In addition, cumulative research has shown that the STAT3 signaling pathway is activated in a variety of tumors, such as breast cancer [71], melanoma [72], brain tumors 
[73], and GC [74, 75], and promotes cell growth and survival, angiogenesis, migration, invasion or metastasis [76].

Su et al. proved that MIR22HG was markedly overexpressed in esophageal cancer (ESCA) tissues through analyzing the TCGA database [29]. Cell experiments revealed that MIR22HG knockdown inhibited cell proliferation, migration and invasion in 3 esophageal adenocarcinoma (EAC) cell lines (OE33, OE19 and FLO-1). Moreover, MIR22HG knockdown suppressed the activity of the STAT3 signaling pathway by downregulating STAT3, c-Myc and p-FAK protein expression, thus inducing apoptosis in EAC cells. These findings revealed a novel MIR22HG-mediated regulatory mechanism of the STAT3 signaling pathway in EAC and may provide new insights into developing lncRNA-based therapies for this cancer (Fig. 3d).

\section{Interactions with proteins}

Another common mechanism by which IncRNAs mediate their functions is through interactions with proteins. LncRNAs can function as protein decoys to recruit or sequester proteins or act as scaffolds linking different proteins, either coordinately or in a complex [77]. LncRNA-protein interactions exert essential functions in posttranscriptional gene regulation, such as splicing, translation, and signaling, thus participating in the progression of various diseases, including cancer [78, 79].

$\mathrm{Su}$ et al. analyzed Seo, TCGA and UM RNA-Seq datasets and found that MIR22HG was significantly downregulated in lung adenocarcinoma (LUAD) tissues compared to normal lung tissues. In addition, a high expression level of MIR22HG was significantly correlated with favorable patient outcomes in two independently published LUAD microarray datasets: Okayama et al. $(P=0.02)$ and Shedden et al. $(P=0.02)$. The authors employed RT-qPCR to confirm that MIR22HG expression levels were significantly lower in LUAD tissues than in normal lung tissues $(\mathrm{P}<0.001)$ and that low MIR22HG expression was correlated with poor patient survival $(\mathrm{P}=0.003)$ in an independent UM cohort including 101 LUAD tissues and 27 normal lung tissues. MIR22HG overexpression suppresses cell proliferation and invasion and induces cell cycle arrest in non-small cell lung cancer (NSCLC) cells. Mechanistically, MIR22HG interacts with and stabilizes YBX1. The MIR22HG-YBX1 complex can bind to the promoter of MET and promote MET expression at both the mRNA and protein levels and inhibit the expression of p21, a potential target of YBX1, leading to the inhibition of proliferation and promotion of apoptosis (Fig. 4a). The dual role of $\mathrm{p} 21$ in the progression of cancer may depend on the cell type, p21 location and p53 status [8082]. Therefore, in different tumors, p21 may have divergent functions. Upregulated p21 is associated with poor survival in patients with glioma and prostate, cervical, ovarian, and esophageal cancers. However, the opposite is observed in other tumors, such as breast, gastric, and ovarian cancers [30]. In this study, the authors revealed the biological role of p21 as a potent oncogene that promotes tumor growth in NSCLC and shed light on a new therapeutic strategy for the regulatory mechanism of p21 mediated by lncRNA-protein interactions [30].

Zhang's team measured MIR22HG levels in a 52patient cohort by qRT-PCR $(P<0.001)$, analyzed TCGA and the GSE14520 cohorts $(P<0.001$ for both cohorts) and revealed that MIR22HG was comparatively expressed at low levels in HCC tissues. Kaplan-Meier analysis of overall survival and disease-free survival (logrank) in the 145-patient cohort and the TCGA cohort revealed that patients with high MIR22HG expression exhibited better overall survival (145-patient cohort: $P=$ 0.001; TCGA cohort: $P=0.015)$ and disease-free survival (145-patient cohort: $P=0.042$; TCGA cohort: $P=0.003$ ) than those with low MIR22HG expression. Functionally, biological studies have revealed that the overexpression of MIR22HG dramatically inhibits cell proliferation, migration and invasion in vitro. Moreover, the overexpression of MIR22HG significantly inhibits tumor growth and metastasis in vivo according to mouse subcutaneous xenograft models and a lung metastasis mouse model. Conversely, the silencing of MIR22HG promotes cell proliferation both in vitro and in vivo. Mechanistically, MIR22HG can interact with the human antigen R (HuR) protein, an RNA-binding protein positively associated with malignant aggressiveness [83-85]. This lncRNAprotein interaction increases MIR22HG stability and regulates the subcellular localization of HuR, resulting in the decreased expression of HuR-stabilized oncogenes such as $\beta$-catenin, CCNB1 (encoding cyclin B1), HIF1A (encoding hypoxia-inducible factor-1 $\alpha$ ), BCL2 (encoding apoptosis regulator $\mathrm{Bcl} 2$ ), $\mathrm{COX} 2$ (encoding cyclooxygenase COX2), and C-FOS (encoding the nuclear phosphoprotein c-Fos) and thereby inhibiting the proliferation, invasion and migration of HCC (Fig. 4b). Importantly, their investigation may help identify potential biomarkers that can improve the diagnosis and treatment of HCC [24].

\section{Interplay with miRNAs as a host gene}

The regulatory relationship between miRNAs and their host genes provides another mechanism for lncRNAmediated gene expression. A previous study described MIR22HG as a host gene of miR-22 [86]. Two independent studies examined whether MIR22HG functions as the host gene of miR-22 in cancer progression (Fig. 5). 


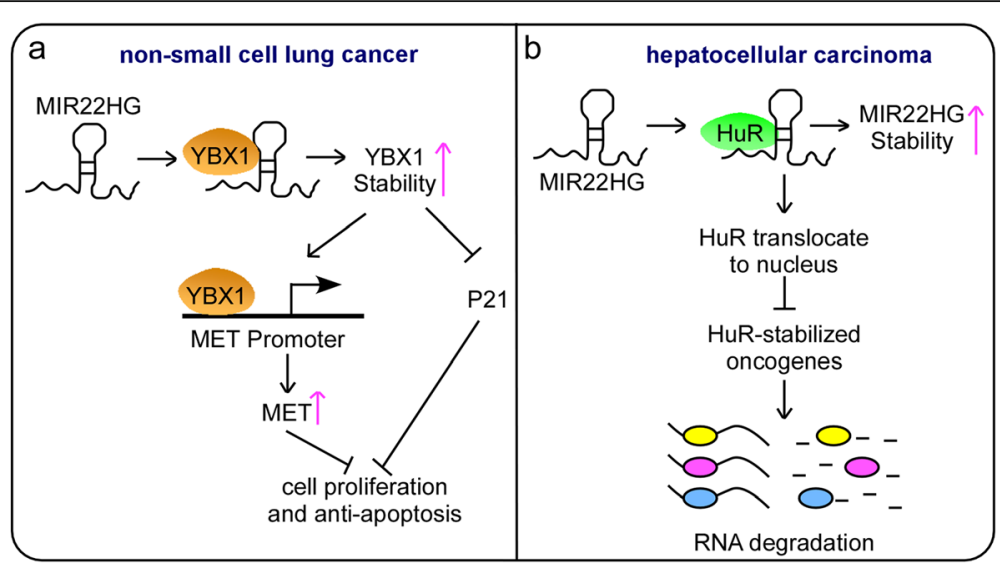

Fig. 4 MIR22HG inhibits tumor progression through interactions with proteins. a MIR22HG interacts with the YBX1 protein, increasing its stability, leading to the upregulation of MET expression and the inhibition of p21 expression, thus suppressing the proliferation and antiapoptosis of NSCLC cells. b MIR22HG specifically interacts with HuR to increase MIR22HG stability and regulate its subcellular localization, resulting in the degradation of HuR-stabilized oncogenes such as $\beta$-catenin, CCNB1, HIF1A, BCL2, COX2, and C-FOS

Han et al. revealed that the expression of MIR22HG was higher in glioblastoma (GBM) and glioma stem-like cells than in normal neural stem cells and that increased MIR22HG was correlated with poor overall survival $(P<$ 0.0001 ) in an analysis of a TCGA dataset. Silencing MIR22HG inhibited GBM cell proliferation and invasion in vitro. In vivo studies in which mouse subcutaneous xenograft and brain orthotopic xenograft models were used have revealed that MIR22HG inhibits tumor growth and metastasis. A mechanistic analysis revealed that MIR22HG, as a host gene of miR-22, is strongly associated with the expression of miR-22-3p and miR-22$5 \mathrm{p}$. Rescue experiments showed that the overexpression of miR-22 is sufficient to restore the MIR22HG depletion-induced inhibition of GBM cell proliferation and invasion. Silencing MIR22HG resulted in the loss of miR-22-3p and miR-22-5p, which upregulated the expression of their direct targets SFRP2 and PCDH15, leading to the inhibition of GBM progression. AC1L6JTK, a specific small-molecule inhibitor, efficiently suppresses tumor growth in vivo by blocking the processing of pre-miR-22 into mature miR-22. These data indicate that the interplay between miR-22 and its host gene MIR22HG might be a potential target for patients with GBM through pharmacological blockade [31] (Fig. 5a). Another independent study confirmed the important role of this interaction in cancer. In addition to its interaction with HuR, Zhang et al. also found that increased MIR22HG could markedly upregulate miR-22$3 p$ expression levels. Additionally, MIR22HG drives miR-22-3p to target HMGB1, leading to the deactivation of HMGB1 signaling. These data demonstrate that miR22-3p and its host gene MIR22HG are coexpressed and functionally coordinated in HCC [24] (Fig. 5b).

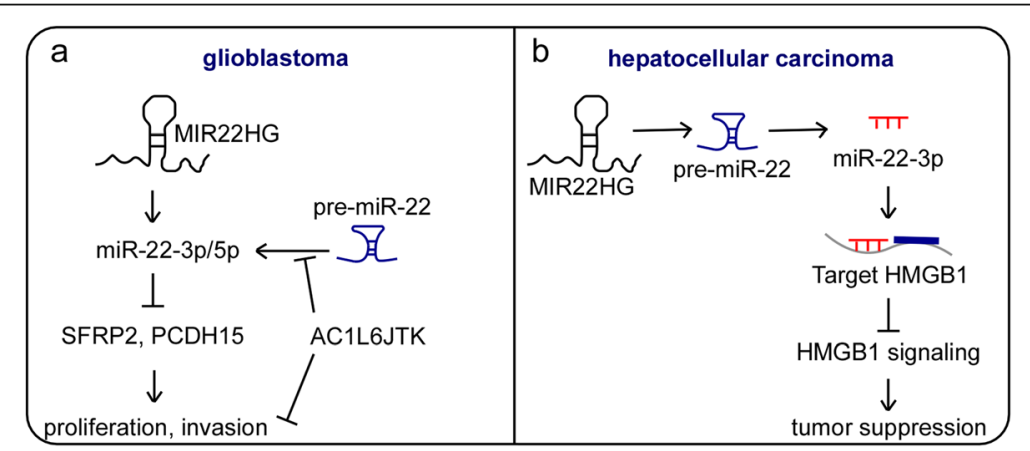

Fig. 5 MIR22HG interacts with miR-22 as a host gene. a MIR22HG, as a host gene of miR-22, upregulates the expression of miR-22-3p/5p, leading to the attenuated expression of its two direct targets, SFRP2 and PCDH15, thus promoting GBM cell proliferation and invasion. AC1L6JTK, a specific smallmolecule inhibitor, efficiently suppresses tumor growth in vivo by blocking the processing of pre-miR-22 into mature miR-22. b MIR22HG markedly upregulates miR-22-3p expression levels and drives miR-22-3p to target HMGB1, leading to the deactivation of HMGB1 signaling 


\section{Therapeutic implications of MIR22HG in cancer}

Currently, MIR22HG is included in a long list of lncRNAs that are mechanistically linked to the progression and prognosis of several types of cancer. It has been reported that MIR22HG is downregulated in GC, HCC, NSCLC, $\mathrm{TC}, \mathrm{CCA}$, and $\mathrm{CRC}$ and that the low expression of MIR22HG is significantly associated with poor overall survival (Table 2). Given the differential expression of MIR22HG in cancer, MIR22HG might be a novel biomarker for cancer diagnosis and prognosis. Not coincidentally, in terms of lncRNAs functioning as biomarkers, one of the most well-known examples is PCA3, a prostatespecific lncRNA previously named DD3 [87]. Considering that PCA3 is prostate tissue-specific and highly overexpressed in prostate cancer (PC) tissues compared with benign tissues, it has attracted the interest of academic researchers who validated the potential role of PCA3 as a biomarker for PC diagnosis [88-92]. Finally, in 2012, the US Food and Drug Administration (FDA) approved Progensa PCA3 as an aid for repeat biopsy decisions in men with a previous negative biopsy [93]. PCA3 is a successful example translated from an academic research laboratory into clinical practice, providing a promising future for lncRNA-based clinical applications.

Overwhelming evidence supports the proproliferative and antiapoptotic roles of MIR22HG in cancer. In addition, MIR22HG exhibits extensive mechanistic diversity to carry out its functional roles; therefore, it may represent a novel target to overcome cancer. Currently, there are several clinical trials involving lncRNAs as novel biomarkers or cancer therapies (database: http:// clinicaltrials.gov). Two clinical trials sponsored by Assiut University will evaluate the clinical utility of detecting the expression of the IncRNA CCAT1 in the diagnosis of CRC patients and its relation to tumor stage (NCT04269746) and investigate the lncRNAs HOTAIR and Midkine as biomarkers in TC. Furthermore, two other clinical trials are recruiting patients to validate lncRNAs as biomarkers for the detection and prognosis of lung cancer (NCT03830619) and high-grade serous ovarian cancer (HGSOC) (NCT03738319). A trial sponsored by Fudan University is currently enrolling subjects to compare the efficacy and safety between docetaxel combined with doxorubicin (epirubicin) and cyclophosphamide followed by gemcitabine combined with cisplatin and doxorubicin (epirubicin) combined with cyclophosphamide followed by docetaxel for high-risk triple-negative breast cancer predicted by the mRNAIncRNA integrated signature and to validate the efficacy of the signature (NCT02641847). Importantly, the development of new RNA biology technologies and approaches offers more opportunities for lncRNA-targeted clinical applications. For instance, small interfering RNAs (siRNAs) and antisense oligonucleotides (ASOs) are the most common RNA-targeted therapies. To efficiently and safely target RNA, some chemical modifications, such as nucleoside moieties, morpholinos, and peptide nucleic acids, can be introduced [94]. The biological function of MIR22HG in cancer will need to be explored in more detail, and its possible relevance to cancer therapeutic targets will also need to be examined.

Another potentially exciting use for MIR22HG may be in the area of immunotherapy. Immunotherapy is a type of cancer treatment that helps the immune system fight cancer. Checkpoint inhibitors are a type of immunotherapy that takes the brakes off the immune system and helps it recognize and attack cancer cells [95]. Although checkpoint inhibitors have made large breakthroughs in cancer treatment, remarkable responses are currently limited to a minority of patients and indications. Thus, one major concern is how we can enhance the efficiency and response rate of checkpoint inhibitors. Notably, checkpoint inhibitors do not work directly on the tumor, but their efficiency depends on whether the patient's own T cells can infiltrate the tumor [96]. $\mathrm{Xu}$ and colleagues revealed that MIR22HG expression is significantly correlated with CD8A and that the overexpression of MIR22HG triggers $\mathrm{T}$ cell infiltration, which plays a central role in coordinating distinct types of immune responses. In this regard, MIR22HG may be a novel biomarker to predict the immunotherapy response. Further in vivo studies confirmed that mice treated with MIR22HG and PD-L1 blockade had smaller size and lower weight tumor and responded more positively to anti-PD-L1 immunotherapy than untreated mice. These findings in mice also correlate with studies of $\mathrm{T}$ cell infiltration as a key limiting factor for efficacious cancer immunotherapy.

\section{Conclusion}

Up-to-date studies have provided a comprehensive overview showing that MIR22HG is recognized as a regulator of cancer-influencing proliferation, apoptosis, and migration. MIR22HG drives the cancer phenotype through the dysregulation of oncogenic and tumor suppressive gene networks via the variety of mechanisms discussed above. Of note, its aberrant expression is closely correlated with clinicopathological parameters, such as lymphatic metastasis, tumor stage, tumor size and overall survival, providing a great opportunity as a cancer prognostic biomarker. Furthermore, with diverse modulatory mechanisms, MIR22HG has advantages that support its potential as a therapeutic target. To date, research on the mechanism of MIR22HG has made some progress but remains mainly in the preclinical stage. Future investigations will be necessary to explore the precise molecular regulatory mechanisms of MIR22HG in carcinogenesis and cancer progression to translate MIR22HG from basic research into the clinic as early as possible. 


\section{Abbreviations}

ncRNAs: Noncoding RNAs; IncRNA: Long noncoding RNA; ceRNA: Competing endogenous RNA; TC: Thyroid carcinoma; EC: Endometrial carcinoma; HCC: Hepatocellular carcinoma; CCA: Cholangiocarcinoma; EMT: Epithelialmesenchymal transition; CRC: Colorectal cancer; T-ALL: T cell acute lymphoblastic leukemia; HNSCC: Head and neck squamous cell carcinoma; GC: Gastric cancer; ESCA: Esophageal carcinoma; EAC: Esophageal adenocarcinoma; LUAD: Lung adenocarcinoma; NSCLC: Non-small cell lung cancer; HuR: Human antigen R; CCNB1: Cyclin B1; HIF1A: Hypoxia-inducible factor-1a; COX2: Cyclooxygenase COX2; GBM: Glioblastoma; PC: Prostate cancer; FDA: Food and Drug Administration; PTC: Papillary thyroid carcinoma; siRNAs: Small interfering RNAs; ASOs: Antisense oligonucleotides

\section{Acknowledgements}

Not applicable.

\section{Authors' contributions}

LZ and CXL contributed to literature review; XLS contributed to designing the manuscript; $L Z$ and $C X L$ contributed to drafting the manuscript; $L Z$ and XLS contributed to editing and revising the manuscript. All authors read and approved the final manuscript.

\section{Funding}

This work was supported by the National Natural Science Foundation of China (81960560), Autonomous Region Science and Technology Achievement Transformation Fund (CGZH2018149), and Natural Science Foundation of Inner Mongolia Autonomous Region (2020BS08002).

\section{Availability of data and materials}

Not applicable.

\section{Ethics approval and consent to participate}

Not applicable.

\section{Consent for publication}

Not applicable.

\section{Competing interests}

The authors declare that they have no competing interests.

\section{Received: 29 July 2020 Accepted: 20 November 2020}

\section{Published online: 03 December 2020}

\section{References}

1. Guttman M, Amit I, Garber M, French C, Lin MF, Feldser D, et al. Chromatin signature reveals over a thousand highly conserved large non-coding RNAs. in mammals. Nature. 2009;458:223-7.

2. Mercer TR, Dinger ME, Mattick JS. Long non-coding RNAs: insights into functions. Nat Rev Genet. 2009;10:155-9.

3. St Laurent G, Wahlestedt C, Kapranov P. The Landscape of long noncoding RNA classification. Trends Genet. 2015;31:239-51.

4. Han Z, Xue W, Tao L, Lou Y, Qiu Y, Zhu F. Genome-wide identification and analysis of the eQTL IncRNAs in multiple sclerosis based on RNA-seq data. Brief Bioinform. 2020;21:1023-37.

5. Chen Y, Xie H, Zou Y, Lai X, Ma L, Liu Y, Li J. Tetracycline-controllable artificial microRNA-HOTAIR + EZH2 suppressed the progression of bladder cancer cells. Mol Biosyst. 2017;13:1597-607.

6. Evans JR, Feng FY, Chinnaiyan AM. The bright side of dark matter: IncRNAs in cancer. J Clin Invest. 2016;126:2775-82.

7. Weidle UH, Birzele F, Kollmorgen G, Rüger R. Long Non-coding RNAs and their Role in Metastasis. Cancer Genomics Proteomics. 2017;14:143-60.

8. Rashid F, Shah A, Shan G. Long Non-coding RNAs. in the Cytoplasm. Genomics Proteomics Bioinformatics. 2016;14:73-80.

9. Kopp F, Mendell JT. Functional Classification and Experimental Dissection of Long Noncoding RNAs. Cell. 2018;172:393-407.

10. Gil N, Ulitsky I. Regulation of gene expression by cis-acting long non-coding RNAs. Nat Rev Genet. 2020;21:102-17.

11. Sun M, Nie F, Wang Y, Zhang Z, Hou J, He D, et al. LncRNA HOXA11-AS Promotes Proliferation and Invasion of Gastric Cancer by Scaffolding the Chromatin Modification Factors PRC2, LSD1, and DNMT1. Cancer Res. 2016; 76:6299-310.
12. Jiang XM, Li ZL, Li JL, Zheng WY, Li XH, Cui YF, Sun DJ. LncRNA CCAT1 as the unfavorable prognostic biomarker for cholangiocarcinoma. Eur Rev Med Pharmacol Sci. 2017;21:1242-7.

13. Li Z, Jiang X, Su Z, Li J, Kang P, Li C, Cui Y. Current insight into a cancerimplicated long noncoding RNA ZFAS1 and correlative functional mechanisms involved. Pathol Res Pract. 2018;214:1517-23.

14. Wang J, Su Z, Lu S, Fu W, Liu Z, Jiang X, Tai S. LncRNA HOXA-AS2 and its molecular mechanisms in human cancer. Clin Chim Acta. 2018:485:229-33.

15. Dai X, Kaushik AC, Zhang J. The Emerging Role of Major Regulatory RNAs in Cancer Control. Front Oncol. 2019;9:920.

16. Esposito R, Bosch N, Lanzós A, Polidori T, Pulido-Quetglas C, Johnson R. Hacking the Cancer Genome: Profiling Therapeutically Actionable Long Noncoding RNAs Using CRISPR-Cas9 Screening. Cancer Cell. 2019;35:545-57.

17. Li J, Jiang $X$, Li Z, Huang L, Zhou Y, Liu Y, Cui Y. Long noncoding RNA GHET1 in human cancer. Clin Chim Acta. 2019;488:111-5.

18. Garland W, Jensen TH. Nuclear sorting of RNA. Wiley Interdiscip Rev RNA. 2020;11:e1572.

19. Zhao $X$, He M, Wan $D, Y e Y, H e Y$, Han $L$, et al. The minimum $L O H$ region defined on chromosome 17p13.3 in human hepatocellular carcinoma with gene content analysis. Cancer Lett. 2003;190:221-32.

20. Zheng J, Xiong D, Sun X, Wang J, Hao M, Ding T, et al. Signification of Hypermethylated in Cancer 1 ( $\mathrm{HIC1}$ ) as Tumor Suppressor Gene in Tumor Progression. Cancer Microenviron. 2012;5:285-93.

21. Chen ZB, Cao WL, Su K, Mao M, Zeng XY, Li JH. MIR22HG inhibits cell growth, migration and invasion through regulating the miR-24-3p/p27kip1 axis in thyroid papillary carcinomas. Eur Rev Med Pharmacol Sci. 2019;23: 5851-62.

22. Qin L, Luo JZ, Tang XL, Han CG. Identification of Long Noncoding RNA MIR22HG as a Novel Biomarker in Thyroid Cancer. Pathol Oncol Res. 2019; 25:703-10.

23. Wu Y, Zhou Y, Huan L, Xu L, Shen M, Huang S, Liang L. LncRNA MIR22HG inhibits growth, migration and invasion through regulating the miR-10a-5p/ NCOR2 axis in hepatocellular carcinoma cells. Cancer Sci. 2019;110:973-84.

24. Zhang DY, Zou XJ, Cao CH, Zhang T, Lei L, Qi XL, et al. Identification and Functional Characterization of Long Non-coding RNA MIR22HG as a Tumor Suppressor for. Hepatocellular Carcinoma. Theranostics. 2018;8:3751-65.

25. Cui Z, An X, Li J, Liu Q, Liu W. LncRNA MIR22HG negatively regulates miR141-3p to enhance DAPK1 expression and inhibits endometrial carcinoma cells proliferation. Biomed Pharmacother. 2018;104:223-8.

26. Hu X, Tan Z, Yang Y, Yang P. Long non-coding RNA MIR22HG inhibits cell proliferation and migration in cholangiocarcinoma by negatively regulating the Wnt/ß-catenin signaling pathway. J Gene Med. 2019;21:e3085.

27. Xu J, Shao T, Song M, Xie Y, Zhou J, Yin J, et al. MIR22HG acts as a tumor suppressor via TGFB/SMAD signaling and facilitates immunotherapy in colorectal cancer. Mol Cancer. 2020;19:51.

28. Li H, Wang Y. Long Noncoding RNA (IncRNA) MIR22HG Suppresses Gastric Cancer Progression through Attenuating NOTCH2 Signaling. Med Sci Monit. 2019;25:656-65.

29. Su W, Guo C, Wang L, Wang Z, Yang X, Niu F, et al. LncRNA MIR22HG abrogation inhibits proliferation and induces apoptosis in esophageal adenocarcinoma cells via activation of the STAT3/c-Myc/FAK signaling. Aging (Albany NY). 2019;11:4587-96.

30. Su W, Feng S, Chen X, Yang X, Mao R, Guo C, et al. Silencing of Long Noncoding RNA MIR22HG Triggers Cell Survival/Death Signaling via Oncogenes YBX1, MET, and p21 in Lung Cancer. Cancer Res. 2018;78:3207-19.

31. Han M, Wang S, Fritah S, Wang X, Zhou W, Yang N, et al. Interfering with long non-coding RNA MIR22HG processing inhibits glioblastoma progression through suppression of Wnt/ß-catenin signalling. Brain. 2020;143:512-30.

32. Dai Q, Li J, Zhou K, Liang T. Competing endogenous RNA: A novel posttranscriptional regulatory dimension associated with the progression of cancer. Oncol Lett. 2015;10:2683-90.

33. Wang Y, Lu T, Wo Y, Sun X, Li S, Miao S, et al. Identification of a putative competitive endogenous RNA network for lung adenocarcinoma using. TCGA datasets. PeerJ. 2019;7:e6809.

34. Salmena L, Poliseno L, Tay Y, Kats L, Pandolfi PP. A ceRNA hypothesis: the Rosetta Stone of a hidden. RNA language? Cell. 2011;146:353-8.

35. Cesana M, Cacchiarelli D, Legnini I, Santini T, Sthandier O, Chinappi M, et al. A long noncoding RNA controls muscle differentiation by functioning as a competing endogenous RNA. Cell. 2011;147:358-69.

36. Tay Y, Rinn J, Pandolfi PP. The multilayered complexity of ceRNA. crosstalk competition. Nature. 2014;505:344-52. 
37. Zhao G, Fu Y, Su Z, Wu R. How Long Non-Coding RNAs and MicroRNAs Mediate the Endogenous RNA Network of Head and Neck Squamous Cell Carcinoma: a Comprehensive Analysis. Cell Physiol Biochem. 2018;50:332-41.

38. Liu Y, Zhang Y, Wu H, Li Y, Zhang Y, Liu M, et al. miR-10a suppresses colorectal cancer metastasis by modulating the epithelial-to-mesenchymal transition and anoikis. Cell Death Dis. 2017:8:e2739.

39. Zeng T, Li G. MicroRNA10a enhances the metastatic potential of cervical cancer cells by targeting phosphatase and tensin homologue. Mol Med Rep. 2014;10:1377-82.

40. Liu S, Sun J, Lan Q. TGF-beta-induced miR10a/b expression promotes human glioma cell migration by targeting PTEN. Mol Med Rep. 2013;8: $1741-6$.

41. Foley NH, Bray I, Watters KM, Das S, Bryan K, Bernas T, et al. MicroRNAs 10a and $10 \mathrm{~b}$ are potent inducers of neuroblastoma cell differentiation through targeting of nuclear receptor corepressor 2. Cell Death Differ. 2011;18:1089-98.

42. Siebel C, Lendahl U. Notch Signaling in Development, Tissue Homeostasis, and Disease. Physiol Rev. 2017;97:1235-94.

43. Steinhart Z, Angers S. Wnt signaling in development and tissue homeostasis. Development. 2018; 145.

44. Vander Ark A, Cao J, Li X. TGF-beta receptors: In and beyond TGF-beta signaling. Cell Signal. 2018;52:112-20.

45. Sever R, Brugge JS. Signal transduction in cancer. Cold Spring Harb Perspect Med. 2015; 5 .

46. Perugorria MJ, Olaizola P, Labiano I, Esparza-Baquer A, Marzioni M, Marin $\mathrm{JJG}$, et al. Wnt-beta-catenin signalling in liver development, health and disease. Nat Rev Gastroenterol Hepatol. 2019;16:121-36.

47. Mohammed MK, Shao C, Wang J, Wei Q, Wang X, Collier Z, et al. Wnt/betacatenin signaling plays an ever-expanding role in stem cell self-renewal. tumorigenesis cancer chemoresistance. Genes Dis. 2016;3:11-40.

48. Lecarpentier Y, Schussler O, Hebert IL, Vallee A. Multiple Targets of the Canonical WNT/beta-Catenin Signaling in Cancers. Front Oncol. 2019;9:1248.

49. Tang L, Wen JB, Wen P, Li X, Gong M, Li Q. Long non-coding RNA LINC01314 represses cell migration, invasion, and angiogenesis in gastric cancer via the Wnt/ß-catenin signaling pathway by down-regulating KLK4 Cancer Cell Int. 2019;19:94.

50. Ng LF, Kaur P, Bunnag N, Suresh J, Sung ICH, Tan QH, et al. WNT Signaling in Disease. Cells. 2019; 8.

51. Lee SY, Lim TG, Chen H, Jung SK, Lee HJ, Lee MH, et al. Esculetin suppresses proliferation of human colon cancer cells by directly targeting beta-catenin. Cancer Prev Res (Phila). 2013;6:1356-64.

52. Wang B, Tian T, Kalland KH, Ke X, Qu Y. Targeting Wnt/beta-Catenin Signaling for Cancer Immunotherapy. Trends Pharmacol Sci. 2018;39:648-58.

53. Perry JM, Tao F, Roy A, Lin T, He XC, Chen S, et al. Overcoming Wnt-betacatenin dependent anticancer therapy resistance in leukaemia stem cells. Nat Cell Biol. 2020;22:689-700.

54. Yuan $S$, Tao F, Zhang X, Zhang Y, Sun X, Wu D. Role of Wnt/beta-Catenin Signaling in the Chemoresistance Modulation of Colorectal Cancer. Biomed Res Int. 2020;2020:9390878

55. Liu L, Zhu H, Liao Y, Wu W, Liu L, Liu L, et al. Inhibition of Wnt/beta-catenin pathway reverses multi-drug resistance and EMT in Oct4(+)/Nanog(+) NSCL C cells. Biomed Pharmacother. 2020;127:110225.

56. Li YJ, Wei ZM, Meng YX, Ji XR. Beta-catenin up-regulates the expression of cyclinD1, c-myc and MMP-7 in human pancreatic cancer: relationships with carcinogenesis and metastasis. World J Gastroenterol. 2005;11:2117-23.

57. Hoffman B, Amanullah A, Shafarenko M, Liebermann DA. The protooncogene c-myc in hematopoietic development and leukemogenesis. Oncogene. 2002;21:3414-21.

58. Sankar N, Kadeppagari RK, Thimmapaya B. c-Myc-induced aberrant DNA synthesis and activation of DNA damage response in p300 knockdown cells. J Biol Chem. 2009;284:15193-205.

59. Salton F, Volpe MC, Confalonieri M. Epithelial-Mesenchymal Transition in the Pathogenesis of Idiopathic Pulmonary Fibrosis. Medicina (Kaunas). 2019; 55.

60. Li Z, Chen Y, An T, Liu P, Zhu J, Yang H, et al. Nuciferine inhibits the progression of glioblastoma by suppressing the SOX2-AKT/STAT3-Slug signaling pathway. J Exp Clin Cancer Res. 2019;38:139.

61. Scanlon CS, Van Tubergen EA, Inglehart RC, D'Silva NJ. Biomarkers of epithelial-mesenchymal transition in squamous cell carcinoma. J Dent Res. 2013;92:114-21.

62. Yang L, Pang Y, Moses HL. TGF-beta and immune cells: an important regulatory axis in the tumor microenvironment and progression. Trends Immunol. 2010;31:220-7.
63. Mariathasan S, Turley SJ, Nickles D, Castiglioni A, Yuen K, Wang Y, et al. TGFbeta attenuates tumour response to PD-L1 blockade by contributing to exclusion of T cells. Nature. 2018;554:544-8.

64. Bray SJ. Notch signalling in context. Nat Rev Mol Cell Biol. 2016;17:722-35.

65. Koveitypour Z, Panahi F, Vakilian M, Peymani M, Seyed Forootan F, Nasr Esfahani MH, Ghaedi K. Signaling pathways involved in colorectal cancer progression. Cell Biosci. 2019;9:97.

66. Lobry C, Oh P, Mansour MR, Look AT, Aifantis I. Notch signaling: switching an oncogene to a tumor suppressor. Blood. 2014;123:2451-9.

67. Nowell CS, Radtke F. Notch as a tumour suppressor. Nat Rev Cancer. 2017; 17:145-59.

68. Yu H, Lee H, Herrmann A, Buettner R, Jove R. Revisiting STAT3 signalling in cancer: new and unexpected biological functions. Nat Rev Cancer. 2014;14: 736-46.

69. Yang L, Lin S, Xu L, Lin J, Zhao C, Huang X. Novel activators and smallmolecule inhibitors of STAT3 in cancer. Cytokine Growth Factor Rev. 2019; 49:10-22.

70. Miklossy G, Hilliard TS, Turkson J. Therapeutic modulators of STAT signalling for human diseases. Nat Rev Drug Discov. 2013;12:611-29.

71. Ma JH, Qin L, Li X. Role of STAT3 signaling pathway in breast cancer. Cell Commun Signal. 2020;18:33.

72. Lesinski GB. The potential for targeting the STAT3 pathway as a novel therapy for melanoma. Future Oncol. 2013; 9:925-927.

73. Garg N, Bakhshinyan D, Venugopal C, Mahendram S, Rosa DA, Vijayakumar T, et al. CD133(+) brain tumor-initiating cells are dependent on STAT3 signaling to drive medulloblastoma recurrence. Oncogene. 2017;36:606-17.

74. Hajimoradi M, Mohammad Hassan Z, Ebrahimi M, Soleimani M, Bakhshi M, Firouzi J, Samani FS. STAT3 is Overactivated in Gastric Cancer Stem-Like Cells. Cell J. 2016;17:617-28.

75. Koh JS, Joo MK, Park JJ, Yoo HS, Choi Bl, Lee BJ, et al. Inhibition of STAT3 in gastric cancer: role of pantoprazole as SHP-1 inducer. Cell Biosci. 2018;8:50.

76. Vasquez-Dunddel D, Pan F, Zeng Q, Gorbounov M, Albesiano E, Fu J, et al. STAT3 regulates arginase-I in myeloid-derived suppressor cells from cancer patients. J Clin Invest. 2013;123:1580-9.

77. Li Z, Zhao W, Wang M, Zhou X. The Role of Long Noncoding RNAs in Gene Expression Regulation. In: Vlachakis D, editor. Gene Expression Profiling in Cancer. London: IntechOpen; 2019. pp. 1-17.

78. Hu H, Zhu C, Ai H, Zhang L, Zhao J, Zhao Q, Liu H. LPI-ETSLP: IncRNAprotein interaction prediction using eigenvalue transformation-based semisupervised link prediction. Mol Biosyst. 2017;13:1781-7.

79. Zhang W, Yue X, Tang G, Wu W, Huang F, Zhang X. SFPEL-LPI: Sequencebased feature projection ensemble learning for predicting LncRNA-protein interactions. PLoS Comput Biol. 2018;14:e1006616.

80. Parveen A, Akash MS, Rehman K, Kyunn WW. Dual Role of p21 in the Progression of Cancer and Its Treatment. Crit Rev Eukaryot Gene Expr. 2016; 26:49-62.

81. Georgakilas AG, Martin OA, Bonner WM. p21: A Two-Faced. Genome Guardian. Trends Mol Med. 2017;23:310-9.

82. Shamloo B, Usluer S. p21 in Cancer Research. Cancers (Basel). 2019; 11.

83. Liu R, Wu K, Li Y, Sun R, Li X. Human antigen R: A potential therapeutic target for liver diseases. Pharmacol Res. 2020;155:104684.

84. Schultz CW, Preet R, Dhir T, Dixon DA, Brody JR. Understanding and targeting the disease-related RNA binding protein human antigen R (HuR). Wiley Interdiscip Rev RNA. 2020;11:e1581.

85. Mitsunari K, Miyata Y, Asai A, Matsuo T, Shida Y, Hakariya T, Sakai H. Human antigen $R$ is positively associated with malignant aggressiveness via upregulation of cell proliferation, migration, and vascular endothelial growth factors and cyclooxygenase-2 in prostate cancer. Transl Res. 2016; 175:116-28.

86. Wang J, Xiang G, Zhang K, Zhou Y. Expression signatures of intragenic miRNAs and their corresponding host genes in myeloid leukemia cells. Biotechnol Lett. 2012;34:2007-15.

87. Bussemakers MJ, van Bokhoven A, Verhaegh GW, Smit FP, Karthaus HF, Schalken JA, et al. DD3: a new prostate-specific gene, highly overexpressed in prostate cancer. Cancer Res. 1999;59:5975-9.

88. de Kok JB, Verhaegh GW, Roelofs RW, Hessels D, Kiemeney LA, Aalders TW, et al. DD3(PCA3), a very sensitive and specific marker to detect prostate tumors. Cancer Res. 2002;62:2695-8.

89. Tinzl M, Marberger M, Horvath S, Chypre C. DD3PCA3 RNA analysis in urinea new perspective for detecting prostate cancer. Eur Urol. 2004;46:182-6. discussion 187. 
90. Groskopf J, Aubin SM, Deras IL, Blase A, Bodrug S, Clark C, et al. APTIMA PCA3 molecular urine test: development of a method to aid in the diagnosis of prostate cancer. Clin Chem. 2006;52:1089-95.

91. Deras IL, Aubin SM, Blase A, Day JR, Koo S, Partin AW, et al. PCA3: a molecular urine assay for predicting prostate biopsy outcome. J Urol. 2008; 179:1587-92.

92. van Poppel H, Haese A, Graefen M, de la Taille A, Irani J, de Reijke T, et al. The relationship between Prostate CAncer gene 3 (PCA3) and prostate cancer significance. BJU Int. 2012;109:360-6.

93. Loeb S. Prostate cancer: Predicting prostate biopsy results-PCA3 versus phi. Nat Rev Urol. 2015;12:130-1.

94. Crooke ST, Witztum JL, Bennett CF, Baker BF. RNA-Targeted Therapeutics. Cell Metab. 2018;27:714-39.

95. Wei SC, Duffy CR, Allison JP. Fundamental Mechanisms of Immune Checkpoint Blockade Therapy. Cancer Discov. 2018;8:1069-86.

96. Melero I, Rouzaut A, Motz GT, Coukos G. T-cell and NK-cell infiltration into solid tumors: a key limiting factor for efficacious cancer immunotherapy. Cancer Discov. 2014;4:522-6.

\section{Publisher's Note}

Springer Nature remains neutral with regard to jurisdictional claims in published maps and institutional affiliations.

Ready to submit your research? Choose BMC and benefit from:

- fast, convenient online submission

- thorough peer review by experienced researchers in your field

- rapid publication on acceptance

- support for research data, including large and complex data types

- gold Open Access which fosters wider collaboration and increased citations

- maximum visibility for your research: over $100 \mathrm{M}$ website views per year

At BMC, research is always in progress.

Learn more biomedcentral.com/submissions 